\title{
Prediction and increasing of general level of students' endurance by the exercises of aerobic direction
}

\author{
Grinko V.M. ${ }^{1 \mathrm{ABCDE}}$, Kudelko V.E. ${ }^{2 \mathrm{ABDE}}$, Hlotov Y.O. ${ }^{3 \mathrm{ACDE}}$ \\ ${ }^{1}$ Department of Social and Humanitarian disciplines, Kharkiv Institute of Finance Kyiv National Trade - Economic \\ University, Ukraine \\ ${ }^{2}$ Department of Social and Humanitarian disciplines, Kharkiv Institute of Finance Kyiv National Trade - Economic \\ University, Ukraine \\ ${ }^{3}$ Department of Economics and Mathematical Methods and Information Technologies, Kharkiv Institute of Finance \\ Kyiv National Trade - Economic University, Ukraine
}

Authors' Contribution: A - Study design; B - Data collection; C - Statistical analysis; D - Manuscript Preparation; E - Funds Collection.

\begin{abstract}
Purpose: $\quad$ to test experimentally the level of aerobic activity on the overall endurance of students in groups of table tennis.

Material: $\quad$ The first-year students $(n=106 ; n=53$ - control group, $n=53$ experimental group) took part in the experiment. It was used Cooper's test. It was used a fractal analysis for analyzing the results.

Results: $\quad$ The results point to disadvantages in the students' physical education program. The program is offered for special sports training (table tennis - 75\%) and aerobic classes (cross training and elements of basic aerobics - 25\%). It is shown the method of forecasting. The use of the methodology allowed significantly improve the prediction accuracy and stability of the forecast. This reduces the effect of the duration of the retrospective period on the parameters of the forecast model.

Conclusions: the program of physical education for students with sports orientation (sectional classes, table tennis) is grounded. The program includes aerobic classes (cross training and basic aerobics).

Keywords: $\quad$ aerobic exercise, general endurance, table tennis, the Hurst method, fractal analysis.
\end{abstract}

\section{Introduction}

The problem of improving the process of physical education of students for many years is the subject of attention of specialists [1-3]. An analysis of literary sources shows that the level of physical training, mental and moral strength of the majority of students remains rather low $[4,5]$. This indicates a deterioration in the physical, mental and moral development of the younger generation $[6,7]$, progress in motor activity deficit [810]. Such indicators lead to a deterioration in the health of students.

All these require finding new ways to improve the physical, mental and moral condition of student youth [11, 12]. According to the results of studies [13, 14], students assessed the importance of development of physical qualities as follows:

1) endurance - $41,8 \%, 2$ ) strength - 14,9\%, 3) agility - $13,7 \%, 4)$ flexibility - $12,2 \%, 5$ ) coordination - 9,8\%, 6) speed - 7,6\%.

And their own level of physical fitness was estimated as follows:

1) strength - 22,3\%, 2) coordination - 19,5\%,3) speed - $16,1 \%, 4)$ flexibility - $15,3 \%, 5)$ agility - 14,9\%, 6) endurance - $11,9 \%$.

The above facts indicate that students understand the important effect of endurance and its significance in solving the set tasks of preparation [15]. They also realize that this physical quality in most of them is the worst [14]. Questions for improving the physical training of students have recently been considered in research works of a large number of researchers [16, 17]. Grinko V.M. studied the (c) Grinko V.M., Kudelko V.E., Hlotov Y.O., 2018

doi:10.15561/20755279.2018.0104 effect of aerobic exercise on students' health [18]. Izaak S.I. monitored the physical activity of students [19]. Other studies point to the need: to take into account the individual characteristics of students [20, 21]; formation of an active life position of students [22]; prediction of student success [23, 24]; introduction of objective criteria for assessing the physical development of students [25, 26]; special control during endurance training [27-29].

There is a large number of works where physical qualities and various types of endurance are studied [30, 31]. The authors consider the effect of cross training and elements of basic aerobics on endurance [7, 13, 18]. These approaches have significantly improved overall endurance. The basis of the proposed program is to determine the state of overall endurance on the basis of the Cooper test. However, one can argue about the possibility of endurance development in other areas. An example is a fractal analysis by the Hurst algorithm [32]. In the work of Anis A.A. et al [33] it was investigated the value of the adjusted scale of the Hurst index, which characterizes the fractal time series for the range of independent normal matches of these series. In the work of Clegg R.G. [34] provides practical guidance on measuring the Hurst parameter for time series of different lengths. The use of fractal analysis of time series in the economy was investigated in other papers $[11,12]$. The authors gave a fractal view of the financial turbulence of time series.

In work of Dubnic'kij V.Iu. [3] it was investigated the methods of forecasting time series, which represent the value of securities, taking into account the fractal dimensionality of a number of observations. In such approaches, the results of the run can be represented as 
time series. For fractal analysis of such time series, it is proposed to use the Hurst algorithm [35, 36]. So, in work of Grinko V.M. et al [13] it was proposed algorithm for fractal analysis of short time series for analysis of the average number of errors in playing table tennis. In other works $[11,34]$ the application of chaos theory to fractal analysis of long time series in the economy is investigated.

In other studies, the fractal analysis revealed the following:

- This demonstrates the importance of consideration of gait variability when using treadmills for research or clinical purposes. Treadmill training may induce invariant gait patterns, posing difficulty in translating locomotor skills gained on a treadmill to overground walking conditions [37];

- Interventions that aim to improve gait function in patients with neurological disorders should consider the heterogeneous relationship between gait variability and neurological conditions [38];

- These analysis techniques have provided new insights into how systems (1) maintain pattern stability, (2) transition into new states, and (3) are governed by short-and long-term (fractal) correlational processes at different spatio-temporal scales [39].

Despite the large number of studies, the issue of forecasting the time series of physical education, taking into account their fractal properties, is not well understood. Therefore, this question remains controversial and requires further research.

The purpose of the research: experimentally determine the effect on the general endurance of aerobic exercises (cross training and basic aerobics) in sports-oriented groups (sectional exercises) playing table tennis. Also, justify the need to include these classes in the curriculum of physical education.

Materials and methods.

Participants. The experiment was attended by 106 first-year students $(n=53$ - control group and $n=53$ experimental group). We received informed consent from all the participants to participate in this experiment.

Organization of research. At the first stage, a confirmatory experiment was conducted. The purpose is to establish the identity of control and experimental groups. Determine the initial level of development of the experiment participants. As a result, there was no significant difference between them.

At the second stage implementation of the aerobic training program in table tennis has been carried out. The purpose of this approach is to identify an increase in the level of general and special endurance. The experiment was conducted during the school year from October 2015 to June 2016.

Students of the control group were engaged in the program of a higher educational institution for groups with sports orientation (sectional classes) table tennis. The program consists of the following distribution of educational material: theoretical training, general- physical and special-physical training, technical training, calibration and control standards, competitions. Classes were held four hours a week during academic year [40].

Students of the experimental group were engaged in the program that was developed for increasing the level of general and special endurance. Our approach combines a program for special sports training (table tennis - 75\%) and aerobic classes (cross training and elements of basic aerobics - 25\%) [40]. Until the middle of December, students every fourth lesson engaged in cross-training in the fresh air. Then they went to the hall, where within the experiment they continued to engage in basic aerobics (every fourth lesson). At the end of March, students went to fresh air, where they continued to engage in cross training (every fourth lesson).

At the third stage a repeated comparative experiment was conducted. The purpose of the experiment is to check the degree of aerobic activity on the physical condition of the students. In both groups, control measures were carried out at the level of general endurance. The Cooper test was used [35]. To analyze the results of running on the Cooper test, it is proposed to use fractal analysis. Fractality means self-similarity: on a different scale, the time series maintains its structure. A system of calculations was used which focused on the definition of special endurance of students [13]. To analyze the Cooper test it was used data from the control and experimental groups (Table 1, 2).

Table 1. Results of the Cooper test for the control group

\begin{tabular}{ll}
\hline $\begin{array}{l}\text { Serial number of } \\
\text { the Cooper test }\end{array}$ & $\begin{array}{l}\text { Number of meters passing by } \\
\text { students }\left(Y_{1}\right)\end{array}$ \\
\hline 1 & 109,870 \\
2 & 109,910 \\
3 & 109,915 \\
4 & 109,925 \\
5 & 109.950 \\
6 & 109,980 \\
7 & 110,005 \\
\hline
\end{tabular}

Table 2. Results of the Cooper test for the experimental group

\begin{tabular}{ll}
\hline $\begin{array}{l}\text { Serial number of } \\
\text { the Cooper test }\end{array}$ & $\begin{array}{l}\text { Number of meters passing by } \\
\text { students }\left(Y_{2}\right)\end{array}$ \\
\hline 1 & 109,610 \\
2 & 109,790 \\
3 & 110,015 \\
4 & 110,300 \\
5 & 110,55 \\
6 & 111,95 \\
7 & 111,20 \\
\hline
\end{tabular}

According to the algorithm of finding the Hurst index and the data of the table 1 let's calculate the Hurst parameters. This allows you to determine the time series and establish its persistence or anti-persistence [32]. This makes it relatively simple and reliable to choose 
the method of forecasting the further development of the investigated process.

Based on the obtained data we build dependence (Fig. 1) to determine the Hurst indicator of the control group.

The abscissa (X) axis shows the period (n) on a logarithmic scale. The ordinate (Y) shows the corresponding R/S average value on a logarithmic scale.

By the relation (Fig. 1) we find the equation of linear regression in the logarithmic form:

$$
\operatorname{Ln}(\mathrm{R} / \mathrm{S})=0.3696 * \operatorname{Ln}(\mathrm{n})+0,088 .
$$

The linear gradient tangent is the Hurst index $(\mathrm{H}=0,3696)$. Thus (Table 1$)$, the Hurst index lies within the limits $0 \leq \mathrm{H}<0,5$. This kind of data is often referred to as "return to the average" [41]. This, in turn, indicates that appropriate prediction methods can be used to construct the theoretical equation [13].

We make similar calculations for data in table 2 .

We construct a dependence (Fig. 2) to determine the Hurst index of the experimental group.

The abscissa (X) axis shows the period (n) on a logarithmic scale. The ordinate (Y) shows the corresponding R/S average value on a logarithmic scale.
Equation of linear regression in a logarithmic form for an experimental group:

$$
\operatorname{Ln}(\mathrm{R} / \mathrm{S})=0,3907 * \operatorname{Ln}(\mathrm{n})+0,09 .
$$

The linear gradient tangent is the Hurst index $(\mathrm{H}=0,3907)$. Thus, the time series for the experimental group (Table 2) is also an anti-fast clock. Therefore, it is possible to use the same methods of forecasting as for the time series of the control group (Table 1).

Next, we check the result for statistical significance [36]. We use a system of calculations on the example of determining the special endurance [13].

It is established that the time series (Table 1, 2) are antipersistent. This allows them to compare and identify the effects of training methods on the results of overall endurance. The results of the comparison of time series are shown in Fig. 3.

As can be seen from the Fig. 3 methods of increasing overall endurance begin to influence the results after the second test. To estimate the results of the running of the experimental group relative to the control, we use the known relation [42]:

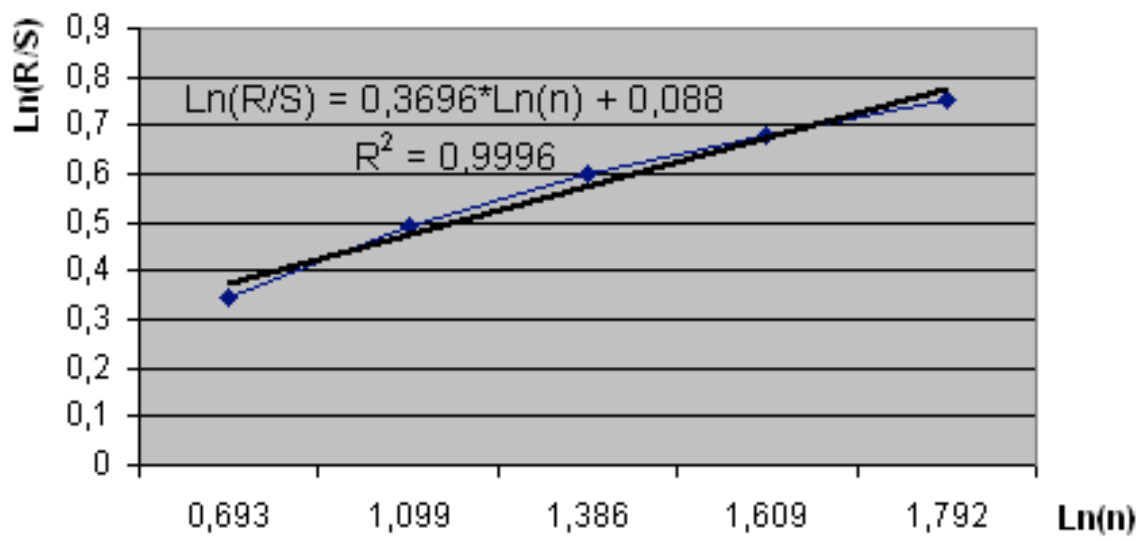

Fig. 1. The dependence $(\operatorname{Ln}(R / S)$ from $\operatorname{Ln}(n)$ (natural logarithm of the average value of $R / S$ on the natural log of the length of the adjacent period $n$ ) of the Cooper test of the control group.

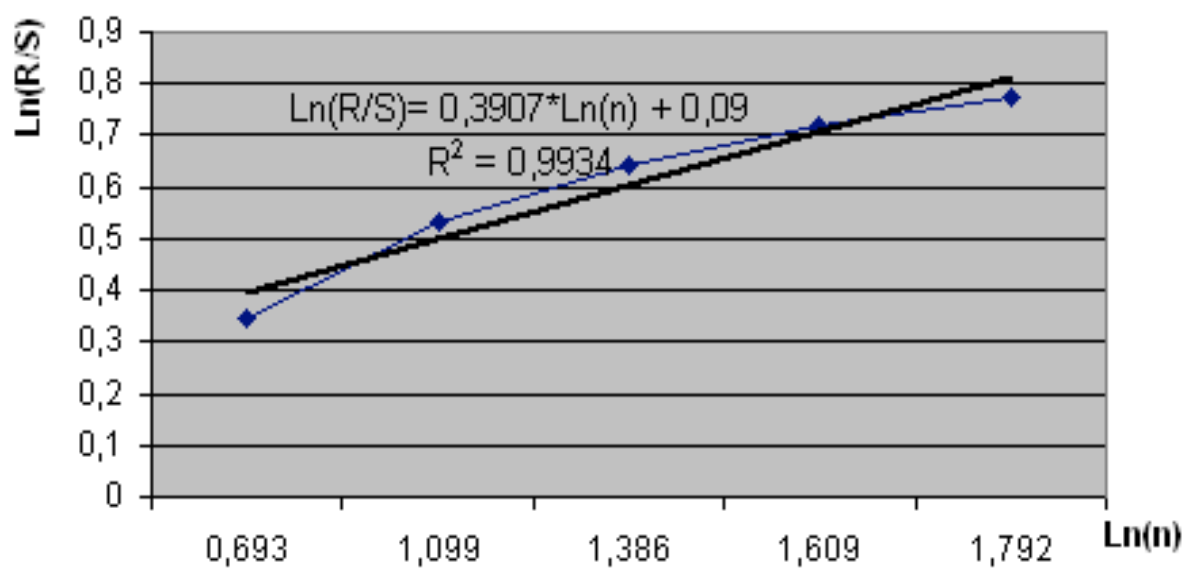

Fig. 2. The dependence of $\operatorname{Ln}(R / S)$ from $\operatorname{Ln}(n)$ (the natural logarithm of the mean value of $R / S$ from the natural logarithm of the length of the adjacent period $n$ ) of the Cooper test of the experimental group. 


$$
\varepsilon=\left[\left(Y_{2}-Y_{1}\right) / Y_{2}\right] / 100,(1)
$$

where $n-$ is number of the Cooper test, $Y_{2}$ - is the results of experimental group, $\mathrm{Y}_{1}-$ is the results of control group, $\varepsilon-$ is the deviation of the results of the experimental group from the control group in \%.

The results of quantitative comparison of the time data of the control and experimental group are summarized in Table. 3.

Statistical analysis: In the study was used a fractal analysis (the Hurst algorithm). For the processing of experimental data it was proposed R/S method. It is made the forecasting of the results for the future to determine the effect of aerobic classes on the level of overall endurance.

\section{Results}

Let's compare control group data at the beginning and at the end of the experiment.

As can be seen, the result of the control group at the end of the experiment improved by $0,135 \mathrm{~m}$. This suggests that the overall endurance of the control group remained almost unchanged.

Next, compare the experimental group data at the beginning and at the end of the experiment.
As can be seen, the result of the experimental group at the end of the experiment improved by 2,01 m. This indicates a significant improvement in the results of overall endurance.

Next, it is made forecasting results for the future. We use the method of exponential smoothing [15, 36]. To calculate this method we use the formula:

$$
\mathrm{U}_{\mathrm{t}+1}=\alpha \times \mathrm{y}_{\mathrm{t}}+(1-\alpha) \times \mathrm{U}_{\mathrm{t}}
$$

where $\mathrm{t}$ is the period preceding the forecast; $\mathrm{t}$ +1 - forecast period; $U_{t}+1$ is a predicted value; $\alpha$ is the smoothing parameter; $U_{t}$ is the actual value of the investigated indicator for the period preceding the forecast; $U_{t}$ is the exponential weighted average for the period preceding the forecast.

When forecasting with the exponential smoothing method, you must choose the smoothing parameter $\alpha$ and the initial value $U_{t}$. When choosing the smoothing parameter $\alpha$ for small numeric rows, all past observations (or almost all) must be taken into account. To do this we use the formula [43]:

$$
\alpha=2 /(n+1),
$$

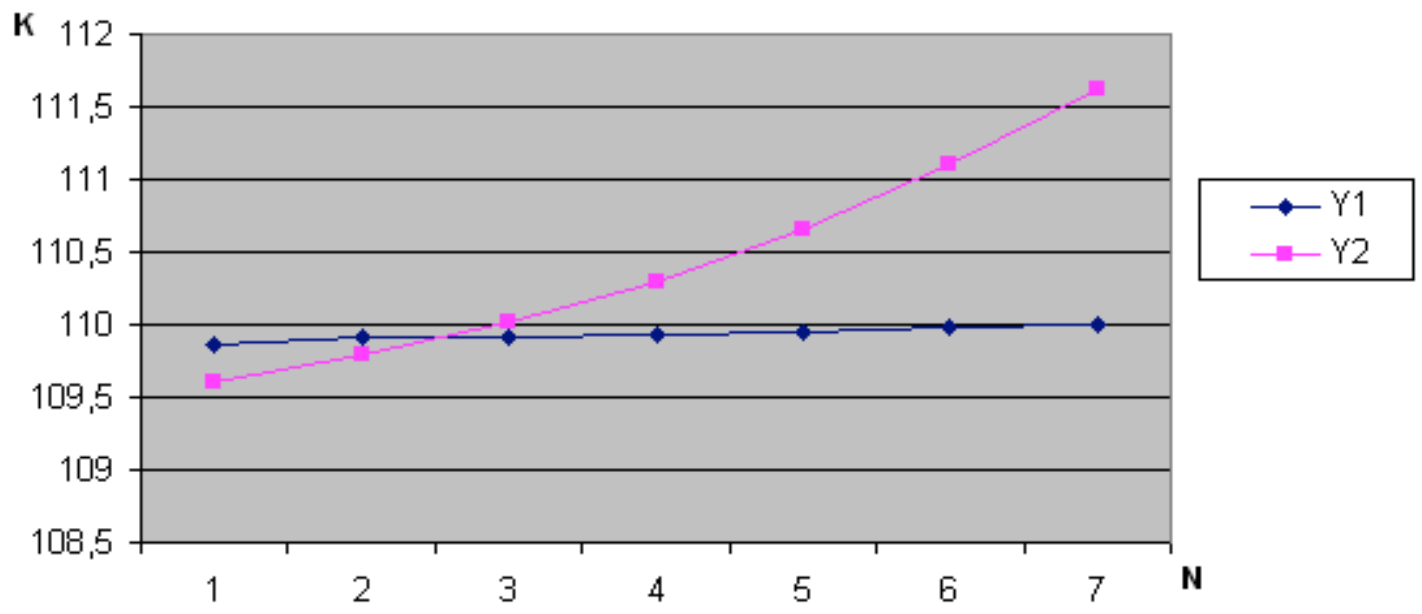

Fig. 3. Comparison of data of control $\left(Y_{1}\right)$ and experimental $\left(Y_{2}\right)$ groups, $\mathbf{K}$ - number of meters passing by students of the control and experimental groups, $\mathbf{N}$ - number of the Cooper test

Table 3. Comparison of time series $Y_{1}$ and $Y_{2}$

\begin{tabular}{llll}
\hline $\begin{array}{l}\text { Serial } \\
\text { number of } \\
\text { the Cooper } \\
\text { test }\end{array}$ & $\begin{array}{l}\text { Number of meters passing by } \\
\text { students of control group in } \mathbf{1 2} \\
\text { minutes }\left(Y_{1}\right)\end{array}$ & $\begin{array}{l}\text { Number of meters passing by } \\
\text { students of experimental group in } \\
12 \text { minutes }\left(Y_{2}\right)\end{array}$ & $\begin{array}{l}\text { Deviation of data } Y_{2} \\
\text { from } Y_{1}, \% \\
\varepsilon=100\left(Y_{2}-Y_{1}\right) / Y_{2}\end{array}$ \\
\hline 1 & & 109,61 & $-0,237$ \\
2 & 109,87 & 109,79 & $-0,109$ \\
3 & 109,91 & 110,015 & 0,091 \\
4 & 109,915 & 110,3 & 0,340 \\
5 & 109,925 & 110,655 & 0,637 \\
6 & 109,95 & 111,095 & 1,004 \\
7 & 109,98 & 111,62 & 1,447 \\
\hline
\end{tabular}




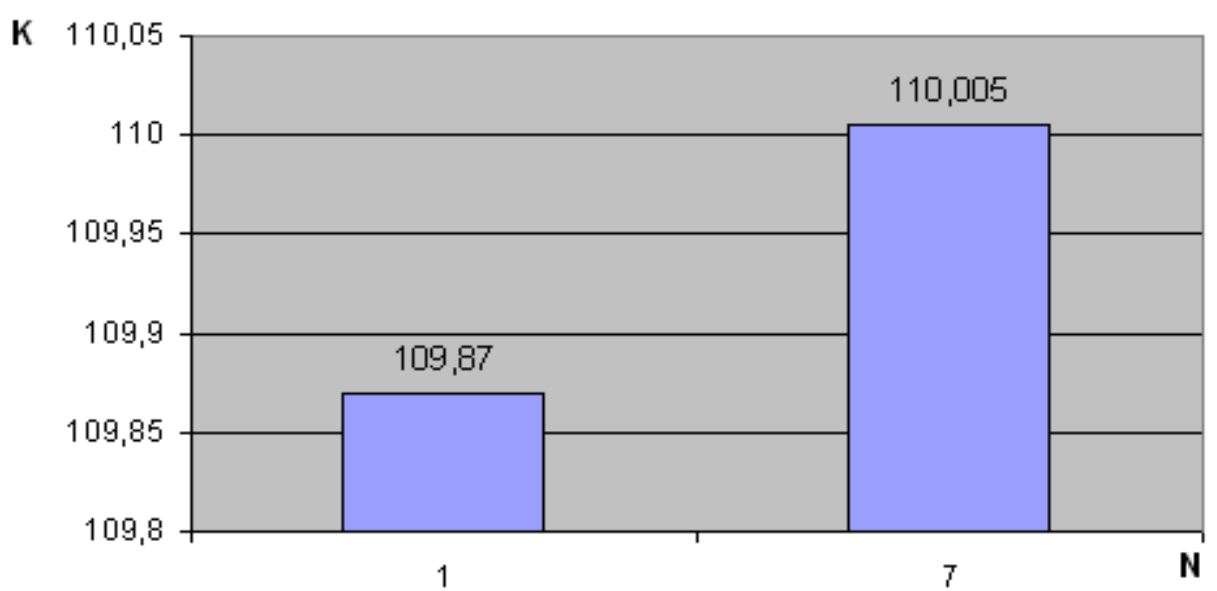

Fig. 4. Comparison of the control group data at the beginning and at the end of the experiment, $\mathbf{K}$ - number of meters passing by the control group students in 12 minutes $\left(\mathrm{Y}_{1}\right), \mathbf{N}$ - number of the Cooper test.

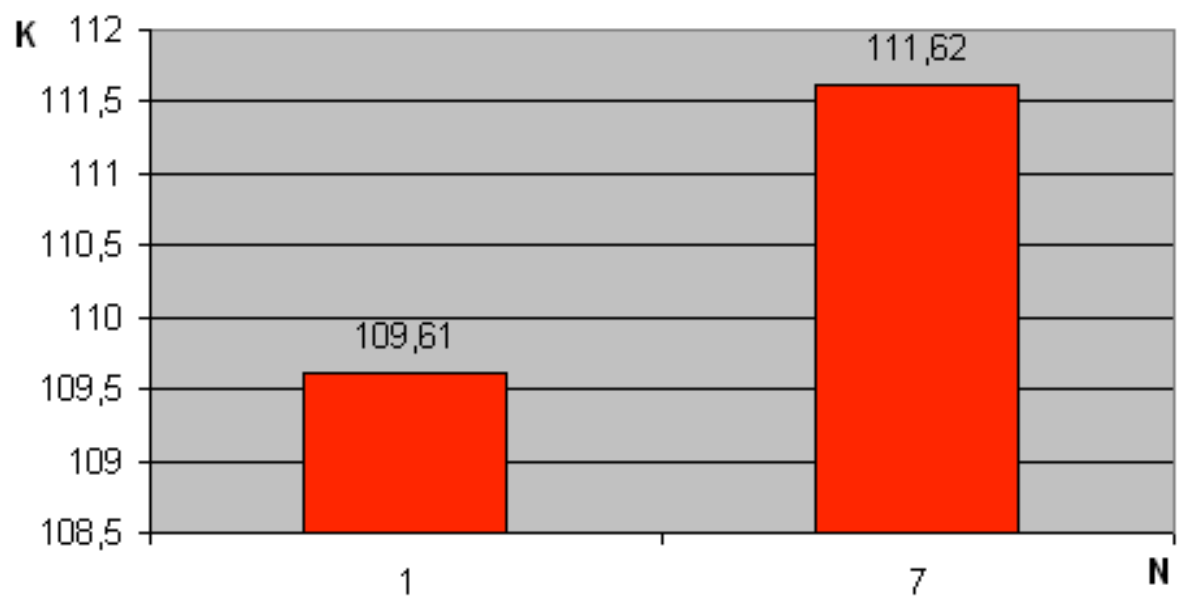

Fig. 5. Comparison of the data of the experimental group at the beginning and the end of the experiment, $\mathbf{K}-$ is the number of meters passing by the students of the experimental group in 12 minutes $\left(\mathrm{Y}_{2}\right), \mathbf{N}-$ number of the Cooper test.

where $\mathrm{n}$ is the number of observations included in the smoothing interval.

The initial value $U_{t}$ can be calculated as the average of all observations (or as the initial first value). For the first method (as the average value of all observations), the initial value $U_{t}=109,936$ (for data $Y_{1}$ ). For data $Y_{2}$ the initial value $U_{t}^{t}=110,440$. For the other method, $U_{t}^{2}=$ 109,87 (for data $Y_{1}$ ). For data $Y_{2}$, the value $U_{t}=109.61$.

Average relative error is calculated according to the formula:

$$
\varepsilon=\frac{1}{n} \cdot \sum_{:=1}^{n} \frac{\left|Y_{1}-U_{t+1}\right|}{Y_{1}} \cdot
$$

We obtain: $\varepsilon=0,031 \%$ for the first calculation method; $0,04 \%$ for the second calculation method. This is much less than $10 \%$, so the forecast accuracy is high.

For the experimental group, similar calculations were made and the average relative error was determined: $\varepsilon=$ $0,52 \%$ for the first calculation method; $\varepsilon=0,54 \%$ for the second calculation method. This is much less than $10 \%$, so the forecast accuracy is high.

\section{Discussion.}

A comparison of our data with the results of other studies $[3,15]$ suggests higher rates of overall endurance of students in our study. The authors of works $[1,4]$ are limited only by the influence of aerobic exercises on general health. Barchukova G.V. et al. [40] use aerobic exercise only at the beginning of the exercise and, finally, during general physical training. The obtained results are supplemented by scientific data on aerobic occupations and their impact on general endurance $[10,13,18]$.

In the study, we used a fractal analysis. One of the advantages of the calculation method is that fractal analysis allows us to identify stochastic (random) time series [33, 34]. In such time series there is no long-term statistical dependence. Stochastic time series can not be predicted by known methods of extrapolation. Its main advantages are the simplicity of the calculation procedure and the ability to record the "weights" of the source information. Using the system of "scales" information can significantly improve the prediction accuracy and stability of the forecast. This reduces the effect of the duration of the retrospective period on the parameters of 
the forecast model. This approach is consistent with the results of another study [44]. The authors propose the use of physiological indicators to predict tennis performance.

Other research on the problems of training athletes also uses forecasting techniques [45-47]. Due to this approach, the authors managed to optimize the physical load on the students and reduce the duration of training. Tests for individual groups of students were classified according to similar approaches [48]. The authors emphasize the combination of methods of forecasting and pedagogical control of motor readiness of students. Our study also shows the ability to predict student outcomes in table tennis lessons. The only difference is the use of different forecasting methods.

Our results suggest a higher effectiveness of the methodological approach to developing a program for students with athletic groups. Such a program combines the usual means of developing physical qualities with an emphasis on special endurance. We have grounded the program of physical education for students of groups with a sports orientation (sectional classes, table tennis). The program includes aerobic classes (cross training and basic aerobics).

\section{Financing}

The work performed in accordance with the thematic plan of research work of the Kharkiv State Academy of Physical Culture "The effect of taking aerobic character on general and special endurance in groups with a sports orientation”.

\section{Conclusions}

The curriculum for sectional tennis lessons includes cross training and elements of basic aerobics. This has more qualitative effect on the development of overall endurance among students. The method of exponential smoothing makes it possible to predict the results for the future.

\section{Conflict of interest}

The authors state that there is no conflict of interest.

\section{References.}

1. Rendi Maria, Szabo Atila, Szabo Tomas, Velenczei Attila, Kovas Arpad. A field study into the effects of exercise characteristics. Psychol, Health. Med. 2008;1:25-32.

2. Wielenga RP, Huisveld IA, Bol E. Exercise training in elderly patients with chronic heart failure. Coron Artery Dis, 1998;9:765-770.

3. Dubnic'kij VIu. The choice of the method of forecasting the value of securities, taking into account the fractal dimensionality of a number of observations. Biznes Inform, 2011;7(1); 120-121. (in Ukrainian)

4. Sharon A Plowman, Denise L Smith. Exercise Physiology for Health, Fitness and Performance. Lippincott Williams \& Wilkins; 2011.

5. World Health Organization. Global recommendations on physical activity for health. Geneva: Switzerland, WHO; 2010.

6. O’Donovan G, Blazevich AJ, Boreham C, Cooper AR, Crank H, Ekelund U, et al. The ABC of Physical Activity for Health: A consensus statement from the British Association of Sport and Exercise Sciences. Journal of Sports Sciences, 2010;28:573-91. doi:10.1080/02640411003671212

7. Kudelko VE. The effectiveness of organizational activities in the system of sports clubs. Fizicheskoe vospitanie studentov tvorcheskikh special'nostej, 2004:3:79-85. (in Russian)

8. Whelton SP, Chin A, Xin X, He J. Effect of aerobic exercise on blood pressure: a meta-analysis of randomized, controlled trials. Ann Intern Med, 2002;136:7493-7503.

9. Bikmukhametov RK. The content of the process of physical education in the system of teacher education. Teoriia $i$ praktika fizicheskoj kul'tury, 2003; 3:45-50. (in Russian)

10.Kudelko VE, Shcherbina ZI, Pavlenko EE. Assessment of physical condition and physical preparedness of students. Kharkov: NPAU; 2003. (in Russian)

11. Mandelbrot B, Hudson R. The (Mis) Behavior of Markets: A Fractal View of Financial Turbulence. Hardcover; 2004.

12.Peters E. Chaos and Order in the Capital Markets. New York: John Wiley; 1991.

13.Grinko VM, Kudelko VE, Hlotov YO. Training of students' special endurance in ping pong sport circles. Physical education of students, 2017;2:52-60. doi:10.15561/207552 79.2017.0201

14.Grinko VM. Attitude of students to physical education and a healthy lifestyle and their self-assessment of the level of physical fitness. Slobozhans'kij naukovo - sportivnij visnik, 2015;1(45):55-59. (in Ukrainian)

15.Kudelko VE, Korolins'ka SV. Analysis of socio-pedagogical foundations of the formation of the needs for independent classes by physical culture at the NFU students. Pedagogics, psychology, medical-biological problems of physical training and sports, 2006;12:93-96.

16.Kriventsova I, Iermakov S, Bartik P, Nosko M, Cynarski WJ. Optimization of student-fencers' tactical training. Ido Movement for Culture-Journal of Martial Arts Anthropology. 2017;17(3):21-30. doi:10.14589/ido.17.3.3

17.Ziolkowski A, Zubrzycki I, Blachnio A, Drobnik P, Zaranska $\mathrm{B}$, Moska W. Influence of sport activity on satisfaction with life and sense of coherence among physically disabled people. Baltic Journal of Health and Physical Activity. 2016;8(4):109-16.

18.Grinko VM. Aerobic classes and their possible impact on the level of general and special endurance of students. Naukovij chasopis NPU imeni M. P. Dragomanova, 2015;12(67):4245. (in Ukrainian)

19.Izaak SI. Physical development and physical preparedness in the system of monitoring the state of physical health of the population. Teoriia i praktika fizicheskoj kul'tury, 2004;11:51-52. (in Russian)

20.Druz VA, Iermakov SS, Nosko MO, Shesterova LY, Novitskaya NA. The problems of students' physical training individualization. Pedagogics Psychology MedicalBiological Problems of Physical Training and Sports. 2017;21(2):51-59. doi:10.15561/18189172.2017.0201

21.Kopeikina EN, Drogomeretsky VV, Kondakov VL, Kovaleva MV, Iermakov SS. Modification of Harvard step-test for assessment of students' with health problems functional potentials. Physical Education of Students. 2016;20(4):4450. doi:10.15561/20755279.2016.0405

22.Kriventsova I, Pashkevych S, Iermakov S, Bartík P, Michal J, Nosko M, Yermakova T. Fitness - aerobic training of 15 
- 17 years' age girl students, who have significant risk of deviations in backbone functional state. Journal of Human Sport and Exercise, 2017;12(4), 1289-1297. doi:10.14198/ jhse.2017.124.15

23.Jagiełło M, Iermakov SS, Nowiński M. Differentiation of the somatic composition of students physical education specialising in various sports. Archives of Budo Science of Martial Arts and Extreme Sports. 2017;13.

24.Podrigalo LV, Galashko MN, Iermakov SS, Rovnaya OA, Bulashev AY. Prognostication of successfulness in armwrestling on the base of morphological functional indicators' analysis. Physical Education of Students. 2017;21(1):46-51. doi:10.15561/20755279.2017.0108

25.Osipov AY, Kudryavtsev MD, Iermakov SS, Jagiello W. Criteria for effective sports selection in judo schools - on example of sportsmanship's progress of young judo athletes in Russian Federation. Archives of Budo. 2017;13:179-186.

26.Podrigalo LV, Iermakov SS, Jagiello W. Special indices of body composition as a criterion of somatic development of martial arts practitioners. Archives of Budo Science of Martial Arts and Extreme Sports. 2017;13:5-12.

27.Gmiat A, Mieszkowski J, Prusik K, Prusik K, Kortas J, Kochanowicz A, et al. Changes in pro-inflammatory markers and leucine concentrations in response to Nordic Walking training combined with vitamin D supplementation in elderly women. Biogerontology 2017:1-14. doi:10.1007/s10522017-9694-8

28.Kortas J, Kuchta A, Prusik K, Prusik K, Ziemann E, Labudda $\mathrm{S}$, et al. Nordic walking training attenuation of oxidative stress in association with a drop in body iron stores in elderly women. Biogerontology 2017: 1-8. doi:10.1007/s10522-0179681-0

29.Jastrzebski Z, Zychowska M, Jastrzebska M, Prusik K, Prusik K, Kortas J, et al. Changes in blood morphology and chosen biochemical parameters in ultra-marathon runners during a $100-\mathrm{km}$ run in relation to the age and speed of runners. International Journal of Occupational Medicine and Environmental Health. 2016;29(5):801-14. doi: 10.13075/ ijomeh.1896.00610

30.Radziminska A, Weber-Rajek M, Lewandowska J, LulinskaKuklik E, Straczynska A, Moska W. Evaluation of the efficacy of low level laser therapy and cryotherapy in the treatment of gonarthrosis. Baltic Journal of Health and Physical Activity. 2016;8(2):87-95.

31.Osipov AY, Kudryavtsev MD, Iermakov SS, Jagiello W. Topics of doctoral and postdoctoral dissertations devoted to judo in period 2000-2016-the overall analysis of works of Russian experts. Archives of Budo. 2017;13:1-10.

32.Hurst HE. Long-term storage capacity of reservoirs. Transactions of the American Society of Civil Engineers, 1951;116(1):770-799.

33.Anis AA, Lloyd EH. The expected value of the adjusted rescaled Hurst range of independent normal summands. Biometrica, 1976; 63:283-298.
34.Clegg RG. A practical guide to measuring the hurst parameter. Computing science technical report. 2005. P. 125-138. No. CS-TR-916.

35.Cooper Kenneth. The Aerobics Way: New Data on the World's Most Popular Exercise Program. Hardcover; 1977.

36.Lykov IA, Okhotnikov SA. The impact of the change in the Hurst function on the possibility of economic forecasting. Fundamental'nye issledovaniia, 2013;10:1539 - 1544. (in Russian)

37.Hollman JH, Watkins MK, Imhoff AC, Braun CE, Akervik KA, Ness DK. A comparison of variability in spatiotemporal gait parameters between treadmill and overground walking conditions. Gait \& Posture. 2016;43:204-209. doi:10.1016/j. gaitpost.2015.09.024

38.Moon Y, Sung J, An RP, Hernandez ME, Sosnoff JJ. Gait variability in people with neurological disorders: A systematic review and meta-analysis. Human Movement Science. 2016;47:197-208. doi:10.1016/j.humov.2016.03.010

39.van Emmerik REA, Ducharme SW, Amado AC, Hamill J. Comparing dynamical systems concepts and techniques for biomechanical analysis. Journal of Sport and Health Science. 2016;5(1):3-13. doi:10.1016/j.jshs.2016.01.013

40.Lebedeva MIu. Analysis of the use of the Brown method for forecasting in marketing research. Marketing $v$ Rossii i za rubezhom, 2008;4:11-15. (in Russian)

41.Gorlach VV, Egorov VL, Ivanov NA. Processing, representation, interpretation of measurement results. Omsk: SibADI; 2006. (in Russian)

42.Najman E. Calculation of the Hurst indicator with the purpose of revealing the trend (persistence) of financial markets and macroeconomic indicators. Ekonomist, 2009;10:25-29. (in Russian)

43.Zagatto AM, Kondric M, Knechtle B, Nikolaidis PT, Sperlich B. Energetic demand and physical conditioning of table tennis players. A study review. Journal of Sports Sciences, 2017;5;1-8.

44.Jagiello W, Kruszewski A. Morphological diversification of competitors training Greco-Roman style of wrestling. Archives of Budo. 2009;5: 147-153.

45.Doroshenko EY, Svatyev AV, Iermakov SS, Jagiełło W. The use of cardio training facilities in training 7-9 year old judo athletes. Archives of Budo Science of Martial Arts and Extreme Sports. 2017;13.

46.Kalina RM, Jagiello W, Chodala A. The result of "testing fights in a vertical posture" as a criterion of talent for combat sports and self-defence - secondary validation (part II: the accuracy). Archives of Budo Science of Martial Arts and Extreme Sports. 2016;12.

47.Khudolii OM, Ivashchenko OV, Iermakov SS, Rumba OG. Computer simulation of junior gymnasts' training process. Science of Gymnastics Journal. 2016;8(3):215-228. 
Information about the authors:

Grinko V.M. (Corresponding author); http://orcid.org/0000-0002-5118-9558; vngrinko78@mail.ru; Department of Social and Humanitarian disciplines, Kharkiv Institute of Finance Kyiv National Trade - Economic University, Ukraine; Lane Pletnivskyy, Kharkiv, 61000, Ukraine.

Kudelko V.E.; http://orcid.org/0000-0001-9252-8563; vikikudelko.11@gmail.com; Department of Social and Humanitarian disciplines, Kharkiv Institute of Finance Kyiv National Trade - Economic University, Ukraine; Lane Pletnivskyy, Kharkiv, 61000, Ukraine.

Hlotov Y.O.; http://orcid.org/0000-0001-8724-7572; glotov1950@ukr.net; Department of Economics and Mathematical Methods and Information Technologies, Kharkiv Institute of Finance Kyiv National Trade - Economic University, Ukraine; Lane Pletnivskyy, Kharkiv, 61000 , Ukraine.

Cite this article as: Grinko VM, Kudelko VE, Hlotov YO. Prediction and increasing of general level of students' endurance by the exercises of aerobic direction. Physical education of students, 2018;22(1):23-30. doi:10.15561/20755279.2018.0104

The electronic version of this article is the complete one and can be found online at: http://www.sportedu.org.ua/index.php/PES/issue/archive

This is an Open Access article distributed under the terms of the Creative Commons Attribution License, which permits unrestricted use, distribution, and reproduction in any medium, provided the original work is properly cited (http://creativecommons.org/licenses/by/4.0/deed.en).

Received: 14.11.2017

Accepted: 12.12.2017; Published: 27.02.2018 